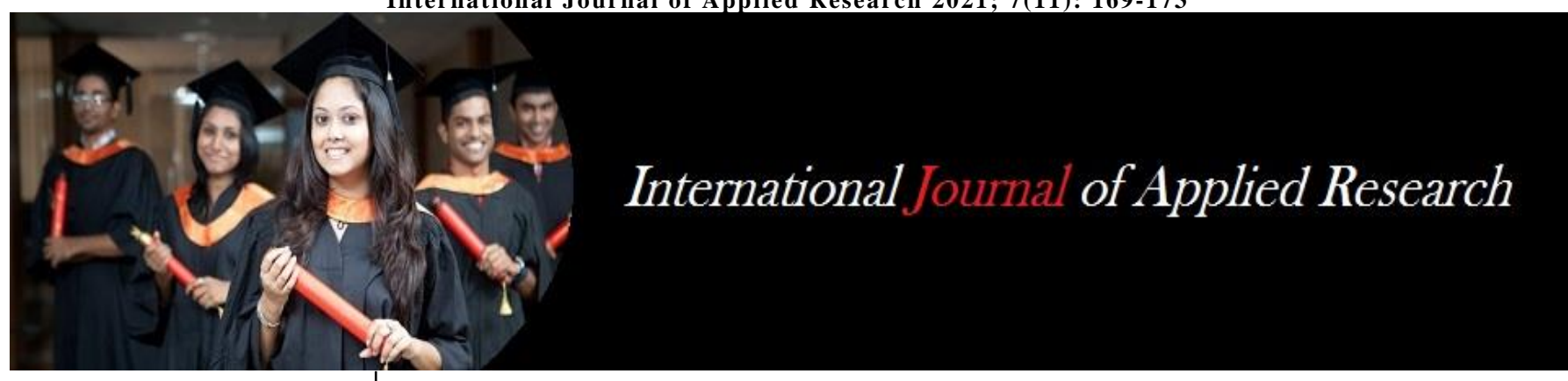

ISSN Print: 2394-7500 ISSN Online: 2394-5869 Impact Factor: 8.4

IJAR 2021; 7(11): 169-173 www.allresearchjournal.com Received: 12-09-2021 Accepted: 18-10-2021

डॉ. मीना राठौर सहायक प्राध्यापक-हिंदी, शासकीय कला एवं वाणिज्य स्नातकोत्तर महाविद्यालय, हरदा, मध्यप्रदेश, भारत
Corresponding Author: डॉ. मीना राठौर सहायक प्राध्यापक-हिंदी, शासकीय कला एवं वाणिज्य स्नातकोत्तर महाविद्यालय, हरदा, मध्यप्रदेश, भारत

\section{मुझे चांद चाहिए - अनंत संभावनाओं के आकाश में होंसलो की उन्मुक्त उड़ान}

\section{डॉ. मीना राठौर}

DOI: https://doi.org/10.22271/allresearch.2021.v7.i11c.9119

\section{प्रस्तावना}

अचानक मुझ में असंभव के लिए आकांक्षा जागी | अपना यह संसार काफी असहनीय है, इसलिए मुझे चंद्रमा, या खुशी चाहिए- कुछ ऐसा, जो वस्तुतः पागलपन-सा जान पड़े | मैं असंभव का संधान कर रहा हूं... देखो, तर्क कहां ले जाता है- शक्ति अपनी सर्वोच्च सीमा तक, इच्छाशक्ति अपने अनंत छोड़ तक; शक्ति तब तक संपूर्ण नहीं होती, जब तक अपने काली नियति के सामने आत्मसमर्पण कर दिया जाए। नहीं, अब वापसी नहीं हो सकती | मुझे आगे बढ़ते ही जाना है......

- कालिगुला

उपन्यास के प्रारंभ में रोमन सम्राट जूलियस सीजर का उक्त कथन उपन्यास की प्रमुख पात्र यशोदा शर्मा उर्फ सिलबिल उर्फ वर्षा वशिष्ठ के जुनून का परिचय देने के लिए सर्वथा उपयुक्त है।

जीवन अनंत संभावनाओं से भरा हुआ उन्मुक्तिआसमान है; जरूरत है हौसलों रूपी पंखों के साथ उड़ान भरने के लिए अदम्य साहस की। सुरेंद्र वर्मा का उपन्यास 'मुझे चाँद चाहिए' स्त्री जीवन के तमाम उतार चढ़ाव के साथ उसकी अदम्य जिजीविषा और साहस का जीवंत उदाहरण है। सिलबिल उर्फ यशोदा शर्मा उर्फ़ वर्षा वशिष्ठ तमाम परेशानियों और हताशा भरे पारिवारिक माहौल में जिस तरह स्वयं को सशक्त बनाए रखती हैं; वह वर्तमान परिवेश की ही कोई स्त्री हो सकती है। हम लाख स्त्री शिक्षा की, स्त्री अधिकार की बात करें; लेकिन हमारे आसपास का परिवेश आज भी स्वतंत्र विचारों के साथ अपने अधिकार और सपनों को साकार करने के लिए उद्धत किसी स्त्री को आसानी से स्वीकार नहीं करता । वह नित नये नियम व परम्परा की बेडियो में उसके सपनों को कैद कर उसे घर की चारदीवारी में एक आश्रित स्त्री के रूप में ही देखना चाहता है। कभी संस्कार कभी परंपरा और कभी मान मर्यादा के नाम पर किसी बहन, बेटी या पत्नी को अपने मानव होने के अधिकार को भूल दासता स्वीकार करनी ही पडती है। हम लाख ढिंढोरा पीटे कि हम 21 वीं सदी में जी रहे हैं; हमारे देश के बेटियां हर क्षेत्र में अपना नाम रोशन कर रही है लेकिन कभी प्रतिशत निकालकर देखा जाये तो स्थिति में कोई विशेष सुधार नजर नहीं आएगा; क्योंकि हम कुछ सफल बेटियों की चर्चा तो आसानी से कर लेते हैं लेकिन जो अनगिनत बेटियां अधिकारों से वंचित की जा रही है उनकी बात नहीं करते।

सिलबिल उर्फ यशोदा शर्मा ऐसे ही भारतीय परिवेश में परंपरागत परिवार में पली बेटी की कहानी है जो जन्म से ही दया का पात्र है; अपने पांच भाई बहनों में एकमात्र सिलबिल ही ऐसी थी की चलती तो चड्डी फिसलती रहती; बहती नाक को फ्राक से पोंछने से उसे कोई परहेज नही होता; बिना गिराए खाना मुहँ में नही जा पाता उसके इस निर्दोष किन्तु दयनीय बचपन को देख परिवार ने उसका सिलबिल नामकरण कर दिया। लेकिन सिलबिल को अपने इन दोनों नामों से ही परहेज न था बल्कि अपने जन्म स्थान को लेकर भी हमेशा कई तरह के सवाल उसके दिलोदिमाग में चलते रहते वह सोचती - "कुछ सवालों का डंक उसे हमेशा चुभता था। वह क्यों पैदा हुई? उसके जीवन का उद्देश्य क्या है?... क्या उसे भी वैसा ही जीवन जीना होगा, जैसा अम्मा, दद्दा और जीजी का है? [1] वह अपने परिवार के अन्य सदस्यों की तरह यथा स्थिति से समझौता करने वाले प्राणी हरगिज़ नहीं थी लेखिका क्षमा शर्मा की पुस्तक स्थित वादी विमर्श स्त्रीत्व वादी विमर्श समाज और साहित्य से एक कथन उद्धत है|" मार्क्स ने कहा था - दुनिया के मजदूरों के पास खोने के लिए कुछ नहीं है, शिवाय अपनी जंजीरों के । लेकिन मजदूरों की जंजीरे टूट भी जाए स्त्रियों की जंजीरे कब टूटेगी? एक अमीर और एक गरीब स्त्री अलग-अलग किस्म की जंजीरों में कैद है।" [2] यशोदा शर्मा उर्फ सिलबिल ने अपनी इन्हीं जंजीरों को 
तोड़ने का दुस्साहस किया और इस दुस्साहस की कीमत चुकाने के लिए भी वह सर्वथा स्वयं को उपस्थित पाती है। होश संभालने के बाद से ही अपने जीवन के प्रति संवेदनशील सिलबिल सबसे बड़े और महत्वपूर्ण बदलाव की शुरुआत अपने नाम से करती है। जब एक दिन किशनदाश शर्मा को अचानक पता चलता है कि"जब संध्या समय शर्माजी को बाजार में मिश्रीलाल इंटर कॉलेज के अध्यापक जनार्दन राय ने बताया कि सिलबिल ने अपना नाम बदल लिया है, तो कुछ पलों के लिए शर्मा जी आवाज रह गए। उन्होंने यह तो सुना था कि फलानी लड़की घर से भाग गई, ढिकानी ने आत्महत्या कर ली, लेकिन ऐसे हादसे से वह अब तक दो-चार नहीं हुए थे |" [3] अपने निर्णय से पिता को भी अचंभे में डालने वाली सिलबिल उर्फ यशोदा शर्मा नाम परिवर्तन का भी सकारण उत्तर देते हुए कहती है-"यशोदा शर्मा नाम में कोई सुंदरता नहीं | वशिष्ठ हमारा गोत्र है | छहों ऋतुओ में मुझे सबसे अच्छी वर्षा लगी |" [4] इस प्रकार सिलबिल उर्फ यशोदा शर्मा ने हाईस्कूल में स्वयं को वर्षा वशिष्ठ नाम से स्वघोषित करने का पहला साहस और परिवार व समाज की नजरों में पहला दुस्साहस पूर्ण कार्य संपत्र किया। जीवन में पहली बार किशनदास शर्मा ने यह महसूस किया कि "कविकुल-तिलक ने ठीक ही कहा है, अपने हाथ से खींचे हुए विष - वृक्ष को अपने ही हाथ से कोई कैसे काट दे।" [5] वर्षा वशिष्ठ का पहला विद्रोह पिता के लिए कुल कलंक के समान था और घर वालो के ह्रदय पर वज्रपात था।

अपने पहले विद्रोह के साथ सिलबिल उर्फ वर्षा वशिष्ठ ने अपने विद्रोही तेवर परिवार को दिखा तो दिए लेकिन आर्थिक बदहाली के चलते उसके बी.ए. करने के ही लाले पड़े थे। फीस के पैसों का कोई इंतजाम होता ना देख वह हर समय अपने भविष्य के लिए चिंतित रहती हैं। अन्य सहपाठियों को भविष्य के बड़े-बड़े सपने देखते हुए देख वर्षा सोचती है - "समर्थ और स्नेहशील पिता बेटी की सुरक्षा एवं खुशी का किस तरह बीमा कर देता है, उसने सोचा था। पर 54 सुल्तानगंज की सिलबिल का क्या होगा?" [6] लेकिन उसे अपने सपनों के लिए अपनों से स्वयं ही संघर्ष करना था यह बात वह बहुत अच्छे से जानती थी; लेकिन सपनों को साकार रूप देने के लिए साहस के साथ उचित मार्गदर्शन की कमी थी; जिसकी पूर्ति के लिए ईश्वर ने उसे मिस कात्याल से मिला दिया था-“अगर मिस दिव्या कात्याल उसके जीवन में ना आती, तो वह या तो आत्महत्या कर चुकी होती या रू रू करते चार - पांच बच्चों को संभालती, किसी क्लर्क की कर्कश, बोसिदी जीवन-संगिनी होती |" [7] लेकिन सिलबिल उर्फ वशिष्ठ का नाम ही अपार संभावनाओं का बोधक साबित होने वाला था। अपनी आगे की पढ़ाई के लिए बच्चों को ट्यूशन पढ़ाने का निर्णय करके वह अपने वंश की सात पीढ़ियों में काम करने वाली पहली कन्या का दर्जा भी प्राप्त कर्ती है।

अपने भविष्य को लेकर चिंतित वर्षा वशिष्ठ जब परिवार के सदस्यों को दो वक्त के भोजन के लिए संघर्ष करते देखती है तो उसे अपने पिता से घृणा होने लगती-- "जब सामर्थ नहीं थी, तो ताबड़तोड़ बच्चे क्यों पैदा किए? परिवार का नियोजन क्यों नहीं किया? क्यों सूअर की तरह इतने पिल्ले पैदा करके कीचड़ में लौटने के लिए छोड़ दि?" [8] जन्म से परिवार में नित नए अभावों के बीच पली वर्षा वशिष्ठ स्वयं को उस दम घोटू माहौल में घुटने से बचाने के लिए किसी भी प्रकार का दुस्साहस करने के लिए तत्पर थी। लेकिन सबसे महत्वपूर्ण सवाल था आखिर इतनी सारी समस्याओं के बीच व्यक्तित्व का प्रश्र कैसे और किस आधार पर उठाया जाए? लेखिका क्षमा शर्मा कहती हैं- "परिवारों में रहने वाले डबल स्टैंडर्ड - लड़की के लिए एक मानक, लड़कों के लिए दूसरे मानक / लड़की बड़ी हुई तो प्रथम कर्तव्य यह कि उसे जैसे-तैसे योग्य - अयोग्य किसी भी लड़के के साथ धक्का दे दिया जाए, हो गया गंगास्नान, कन्यादान, छाती की चट्टानों का हटना | अब जिंदगी-भर पूजो एक
मूर्ख को देवता मानकर" [9] शत प्रतिशत यही स्थिति वर्षा वशिष्ठ की भी थी। परिवार के सभी सदस्य किसी तरह योग्य या अयोग्य के साथ उसका विवाह कर अपने कर्तव्य की इतिश्री करना चाहती थे: लेकिन वर्षा अपनी आत्मनिर्भरता के लिए सतत प्रयासरत है। बी ए करने के बाद भी नौकरी मिलना इतना आसान नहीं यह बात वर्षा अच्छे से जानती थी और उससे भी अच्छे से वह इस बात से वाकिफ थी की 54 सुल्तानगंज के लोग कभी भी उसके दर्द को समझ नहीं पाएंगे-” ये मेरे रक्त संबंधी है, इनका सुख-दुख मेरा है, पर मेरा सुख-दुख मेरा ही रहेगा | ये उसे बाँट नहीं सकेगे | एक हद के बाद उसे समझ भी नही सकेगे |" ${ }^{[10]}$ वर्षा वशिष्ठ यह बात अच्छे से जानती थी की वह ५४ सुल्तानगंज में रहकर कभी भी अपने सपनों को साकार नही कर पाएगी; और घर के अन्य सदस्यों को उसके सपनों और उन्हें पूरा न कर पाने की पीड़ा से कोई सरोकार नहीं नहीं था। वे बस किसी तरह उसका विवाह कर अपनी जिम्मेदारियों से मुक्त होना चाहते थे। लेकिन वर्षा ही थी जो हर कीमत पर अपनी बात पर अडिग थी - "मुझे शादी नहीं करनी है ... अगर तुम लोगों ने जबरदस्ती की, तो मैं कुएं में कूद जाऊंगी " [11] शायद यही एक अंतिम उपाय बचा रह गया हो |

वर्षा के भीतर चल रही उथल-पुथल को अगर किसी ने पहचाना तो वह थी मिस दिव्या कात्याल जिसने ना सिर्फ वर्षा के भीतर छुपी हुई कला को पहचाना वरन उसे एक सही दिशा देने का सार्थक प्रयास भी किया- "तुम्हें अपनी अभिव्यक्ति के लिए एक माध्यम चाहिए। वह क्या होगा, यह मैं अभी पक्के तौर पर नहीं कह सकती। पर एक बार रंगमंच की कोशिश कर लेने में कोई हर्ज नहीं |" [12] मिस कात्याल से मिलते ही वर्षा के जीवन में मार्गदर्शक की कमी ख़त्म हुई: अगर कुछ बाकी रह गया था तो वह था 54 सुल्तानगंज के उन लोगों को समझाना जो उसका परिवार होने का हक जताते थे।

एक तरफ बड़ी बहन थी जो उसे शादी के फायदे गिना रही थी: एक तरफ पिता थे जिन्हें वर्षा का नाटक में काम करना परिवार व खानदान के नाम पर कलंक लगता था। भाई के विवाह पश्चात घर में भाभी की उपस्थिति वर्षा के लिए एक सहयोगी नही वरन एक और चुनौती के रूप में उपस्थित हो गई थी। वह वर्षा को प्रताड़ित करने में कोई कसर नहीं रखती | भारतीय परिवारों में इस तरह के भेदभाव पूर्ण व्यवहार पर लेखिका क्षमा शर्माक लिखती है - "घर जैसे ही माता-पिता से स्थानांतरित होकर भाई भाभी तक पहुंचता है, लड़कियों की दुनिया बदल जाती है। वे उसी दिन कितनी असहाय, कितनी लाचार, कितनी बेचारी हो जाती हैं? [13] यही स्थिति वर्षा की अपने परिवार के बीच में थी। लेकिन इन सबके आरोप वर्षा के निर्णय को बदल नही पाते वः अपने निर्णय पर अडिग रहती है; अपनी बहन को यह तक कहने में नहीं झिझकती कि." मैं सिर्फ मादा नहीं हूं|... आयु के जिस मोड़ पर मैं खड़ी हूं, उसमें शादी मुझे उतने ने महत्व की नहीं लगती, जितना अपने पांव पर खड़ा होना लगता है। ... कुपात्र के साथ बंधने से अकेले रहना अच्छा है| यह मै मानती हूं कि मेरी वजह से घर के लोगों को बाहर दो बातें सुननी पड़ेगी, लेकिन ऐसा होना मेरी मजबूरी होगी |" [14] वर्षा को अपनी महत्वाकांक्षा के साथ परिवार को होने वाली सामाजिक निंदा की भी परवाह है, लेकिन वह जानती है की परिवार के और उसके स्वयं के सुख की परिभाषा अलग-अलग है । अपनी हर कोशिश पर पानी फिरते देख वर्षा अंतिम निर्णय पर पहुंच कर एक दुस्साहस ह कार्य करने से स्वयं को नहीं रोक पाती; उसे लगता है की यह संसार उसे उसके तरीके से जीने नहीं देगा इसलिए वह संसार का त्याग करने का निर्णय लेकर धतूरे के बीज खाकर आत्मदाह का कदम उठाती है।

वर्षा के सपनों को पहली उड़ान एन. एस. डी. था। लेकिन वहाँ तक पहुचने से पहले यहां कई दिक्कतें थी। पिता ने मां की बीमारी और घर की रसोई की जिम्मेदारी का उलाहना दिया लेकिन इसके लिए 
वर्षा पहले से तैयार थी उसने अपने बूते 1 महीने के लिए महारानी का प्रबंध कर दिया ताकि मां को पूरी तरह से आराम मिल सके| लेकिन घरवाले कहीं ना कहीं से किसी दुहाज वर की तलाश कर उसके हाथ पीले करने की जुगाड़ में लगे रहतें ऐसी स्थिति में वर्षा का अपने निर्णय पर अडिग रहना दुष्कर था लेकिन उसने स्पष्ट रूप से अपना मंतव्य जाहिर कर दिया - “यह ब्याह में नहीं करूंगी । तुम लोग चाहे मारो, चाहे कूटो |" [15] अपने सपनों को पूरा करने के लिए उद्धत्त वर्षा घर में बंद क्र दी गयी। भाई और पिता की मार उसके मन पर गहरा असर डालती है फलस्वरूप परिवार से स्रेह रूपी नाता टूट क्र बिखर जाता है- “भाई पिता के साथ संलग्र उसके मन का एक बहुत नाजुक तंतु इस दिन ऐसे टूटा की फिर कभी जुड़ न सका [ ${ }^{[16]}$ लेकिन समझौता करना उसे गवारा नही और यही प्रवती उसे नेशनल स्कूल आफ ड्रामा तक ले जाती है।

एक और जहां वर्षा वशिष्ठ आत्मनिर्भरता हेतु संघर्षरत है; वहीं दूसरी ओर मिस कात्याल आत्मनिर्भर होकर भी मां की खुशी के लिए विवाह के नाम पर अनचाहे रिश्ते में बंध समझौतावादी प्रवृत्ति के साथ स्त्री होने के नाते परिवार के प्रति दायित्व निर्वाहन की पूर्ति हेतु विवश है। वह कहती है -" उनकी खुशी के लिए समझौता कर रही हूं । रोहन के लिए मेरे मन में इज्जत के अलावा और कुछ नहीं। अब मैं तुम्हें चाहती हूं चहकती हुई कैसे दिखाई दूँ |" [17] परिवार की मर्जी, परिवार की प्रतिष्ठा और मान मर्यादा की खातिर एक पढ़ी-लिखी आत्मनिर्भर सुलझे व्यक्तित्व की धनी दिव्या कात्याल जब स्वयं को एक अनचाहे रिश्ते में बंध जाने से रोकने की हिम्मत नहीं जुटा पाती उस परिवेश में दूसरों पर आश्रित आधी आबादी की दशा और दिशा सदियों से परिवार और परंपराएं ही तय करती आ रही हैं; जरूरत है इस सोच में बदलाव की ताकि परिवार और परंपरा के नाम पर आधी आबादी को उसके अधिकारों से वंचित न किया जा सके | बल्कि उनके समग्र व्यक्तित्व को अनंत ऊचाईयों का आसमान मिल सके ।

वर्षा वशिष्ठ का समर्पण उसे नेशनल स्कूल आफ ड्रामा तक लेकर तो आ जाता है पर परिवार वाले अपने अंतिम प्रयास के तहत यहां भी अपनी पारिवारिक प्रतिष्ठा का राग अलाप क् कर उसे वापस ५४ सुल्तानगंज ले जाने की साजिश करते है । एक पिता जिसे अपनी बेटी के अनंत प्रयासों से मिली सफलता के बाद गर्व का अनुभव होना चाहिए वही पिता अपनी बेटी के लिए पत्र लिखता है- “आपको यह पत्र लिखते हुए हुए मुझे दुख हो रहा है, पर एक पिता के नाते मैं विवश हूं |वर्षा मेरी इच्छा के विरुद्ध इस विद्यालय में भर्ती हुई है। अब वह निश्चित विवाह के लिए आने को प्रस्तुत नहीं है। समाज में हमें कैसे कलंक का सामना करना पड़ेगा आप समझ सकते हैं। मेरा आपसे अनुरोध है कि उसे समझाने की कृपा करें। हमारी पारिवारिक प्रतिष्ठा खतरे में है ${ }^{[}{ }^{[18]}$ यह भारतीय परिवेश के ही एक पिता के वचन हो सकते हैं जो एक प्रतिष्ठित संस्था में चयनित अपनी बेटी के भविष्य को बर्बाद करने के लिए लिखा गया एतिहासिक दस्तावेज है।

परंपरागत परिवार और परिवेश में अधिकांश भारतीय घरों में बेटी के जन्म के साथ ही उसके विवाह को लेकर चिंता व्यक्त की जाती है लेकिन उसके केरियर या सपनों की बात तक नहीं की जाती। कोई भी सदस्य यह पूछना नहीं चाहता कि वह अपने जीवन में क्या चाहती हैं? लेकिन हर एक सदस्य उससे क्या चाहता है यह उसे हर दिन एहसास कराया जाता है। वर्षा वशिष्ठ परिवार के किसी सदस्य की उम्मीद पर खरा नहीं उतर पाती; क्योंकि माता, पिता, बहन, जीजा, भाई, भाभी लगभग हर संबंध उससे एकमात्र विवाह की उम्मीद रखता है: जिससे उसे सर्वथा इंकार है।

अपनी आत्मनिर्भरता व सपनों को साकार रूप देने के लिए वर्षा के प्रयास संघर्ष के साथ-साथ उसे अपनों से दूर होने के लिए मजबूर
करते हैं; क्योंकि उसे अब तक समझ नहीं आया कि क्या लड़की होकर जन्म लेने का एकमात्र उद्देश्य विवाह करना होता है? एक वर्ग विशेष में जन्म लेने पर उसे गर्व का अनुभव क्यों नहीं होना चाहिए? अपने व्यक्तिगत निर्णय लेने का अधिकार उसे क्यों नहीं होना चाहिए? अपने स्वतंत्र व्यक्तित्व की चाह और सपनों को जीने की चाहत उसे अपनों से दूर ले जाती है। वह कहती है - जिस तरह आप अपना घर- परिवार नहीं छोड़ सकते-क्योंकि वह आपकी जिंदगी की धुरी है... जिस तरह आपका घर आपकी जिंदगी को सार्थकता देता है. उसी तरह रंगमंच मेरी जिंदगी में ऐसा अर्थ भरता है, जिससे मैं जिंदा रह सकू ।" [19] वर्षा का अदम्य साहस सपनों के प्रति समर्पण उसे रंगमंच के उस शीर्ष तक पहुंचाता है जिसकी उसने कल्पना तक नहीं की थी।

जहां एक और सुल्तानगंज के निवासियों की सोच वर्षा को चूड़ीदार सलवार तक पहनने की इजाजत नहीं देती; वही दिल्ली जैसे अनजान शहर में वर्षा अपने व्यक्तित्व को सर्वोच्च ऊंचाइयों तक ले जाने का प्रयास करने के लिए मुक्त थी; क्योंकि बड़े शहरों में लोगों की सोच का दायरा सीमित नहीं होता। क्षमा शर्मा कहती हैं - "बड़े शहर स्त्रियों को जिंदा रहने और उनके विकास की आजादी देते हैं आज यदि प्रतिशत निकाला जाए तो साक्षर, आत्मनिर्भरता और विचारपूर्ण स्त्रियों की संख्या सबसे अधिक यहीं मिलेगी। दूसरों के मामले में टांग ना अड़ाना महानगर की विशेषता है और दूसरों को जिंदा रहने देने का एक लोकतांत्रिक तरीका भी " [20] शायद यही एक वजह थी की वर्षा वशिष्ठ अपने अभिनय क्षमता को एनएसडीसी में आकर निखार सकी और रंगमंच की दुनिया में अपनी एक अलग पहचान कायम कर सकी।

जिस रंगमंच की दुनिया में अपने कठिन प्रयासों और समर्पण के साथ वर्षा वशिष्ठ एक अलग पहचान कायम करती हैं; उसी रंगमंच की दुनिया ने उसे हर्ष से मिलवाया, जिसके साथ वह अपना अभिनव रिश्ता कायम करती है। हर्ष उसके जीवन के अकेलेपन व संत्रास को दूर कर एक साथी की तरह उसके व्यक्तित्व के कमजोर पहलुओं को दूर कर उसे अपने जीवन और अपने परिवार में भी महत्वपूर्ण स्थान देता है। लेकिन दिव्या कात्याल उसे सहज रूप में इस रिश्ते के प्रति आगाह करते हुए कहती हैं, लेकिन मुझे यह भी लगता है कि बार-बार अनुभव या सुख के लिए ऐसा आचार एक और व्यक्ति के रूप में तुम्हें हीन और दुर्बल बनाएगा दूसरी और नैतिक दृष्टि से भी मलिन करेगा।" ${ }^{221]}$ दिव्या एक दोस्त की तरह वर्षा के आचरण पर न सिर्फ नजर रखती हैं बल्कि उसे नैतिक दायित्व का निर्वाहन भी याद दिलाती है ।

रंगमंच की दुनिया जहां आकर वर्षा वशिष्ठ ने न सिर्फ अपने व्यक्तित्व वरन आत्मनिर्भरता के साथ जीवन जीने का स्वप्र साकार किया था; उसी रंगमंच की अनोखी दुनिया में उसे मित्रों के साथ हर्ष जैसा साथी भी मिला था जिसे उसने बिना किसी सामाजिक सरोकार या विवाह बंधन में बंधे अपना जीवनसाथी स्वीकार लिया था। हर्ष की माँ और बहन उसे अपने परिवार में बहू के रूप में स्वीकृति दे चुकी थी।

सिर्फ अभिनय करने से जिंदगी नहीं चलती; जिंदगी जीने के लिए रुपयों की आवश्यकता होती है, और रुपए कमाने के लिए वर्षा के पास अदम्य साहस था; रंगमंच के लिए अभिनय का हुनर भी था, लेकिन रंगमंच को जितना समय वर्षा से चाहिए था उतना समय वर्षा के पास नहीं था। अभी नाट्य अकादमी से उसका प्रशिक्षण खत्म भी नहीं हुआ और घरवाले उसके हाथ पीले करने पर उतारू हो चुके थे। वर्षा के पास सुल्तानगंज से वापस दिल्ली लौटने के अलावा और कोई उपाय नहीं था; लेकिन दिल्ली आकर उसे पता चलता है कि जिस बरसाती को उसने अपना बसेरा बना रखा था अब वह भी उसकी नहीं रही; क्योंकि बढ़ती महंगाई में मालिक को 
उसका ज्यादा किराया चाहिए था और वर्षा की मजबूरी थी कि वह बढ़ी हुई किराए की राशि चुका पाने में असमर्थ थी | क्योंकि छोटा भाई किशोर बिजली के उपकरण की मरम्मत का कोर्स करने कानपुर में रह रहा था और वर्षा उसे हर माह ₹ 100 भेज रही थी उधर बड़ा भाई तबादले के कारण घर से अन्यत्र चला गया था ऐसी स्थिति में पिता को भी वह ₹ 50 प्रतिमाह मनी ऑर्डर द्वारा भेज रहे थी; अब कोई गुंजाइश नहीं थी कि वह अपनी बरसाती का बढ़ा हुआ किराया दे पाती।

चांदनी चौक में एक स्ट्रीट प्ले को बीच में रोका गया आर कुछ असामाजिक तत्वों द्वारा कलाकारों पर हमला किया गया इसके विरोध में आवाज उठाने हेतु जब वर्षा से अनुरोध किया तो वह बिफर उठी" भाड़ में गई कला और संस्कृति; कला और संस्कृति के लिए अपनी आवाज उठाने से पहले मैं पूछती हूं, तुम्हारी कला और संस्कृति ने मेरे लिए क्या किया? तुम्हारी कला और संस्कृति को पहले यह चाहिए कि मुझे दिल्ली में सस्ती बरसाती दिलवाए |" [22] जिस कला और संस्कृति के लिए वर्षा परिवार और समाज से विद्रोह कर यहां तक पहुंची थी उसी कला संस्कृति ने उसे इस बात का एहसास दिला दिया की रोजमर्रा की जरूरतों को पूरा करने के लिए धन की आवश्यकता होती है कला कि नहीं।

यही नहीं इस रंगमंच की दुनिया में अपनी प्रतिभा दिखाने के लिए उससे अपने ही दोस्तों और मित्रों के साथ प्रतिस्पर्धा करनी होती थी; जिसमें कई बार वह स्वयं आहत होती और कई बार दूसरों को आहत होता महसूस करती थी। रीटा के अचानक एनएसडी छोड़कर जाने पर उसे अपनी प्रतिभा और प्रतिस्पर्धा दोनों पर खेद महसूस होने लगा" प्रतियोगिता का ऐसा करुण परिणाम भी होता है? यह तो पराजय से भी बदतर है, उसने सोचा |" [23] रीटा चंडीगढ़ से आते समय न जाने कितने अरमान साथ लेकर आई थी; लेकिन एक पत्नी और मां के दायित्व के आगे उसकी प्रतिभा और प्रतिस्पर्धा दोनों हार जाते हैं; और वह इन सब से पलायन करने को विवश है लेकिन हर्ष व्यवहारवादी बुद्धि से परिचालित था। उसे रंगमंच से अधिक प्रसिद्धि एवं पैसों से लगाव था। वह फिल्म नगरी की ओर पलायन करता है ताकि कम समय में नाम और दाम दोनों कमा सकें। लेकिन हर्ष का मुंबई पलायन कहीं ना कहीं उन दोनों के बीच दूरियां भी लेकर आता है। हर्ष अपने फिल्मी दुनिया में व्यस्त दौलत और शोहरत दोनों के नजदीक था; लेकिन वर्षा अनचाहे ही भूलभुलैया में झूल रही थी; उसे लगता हर्ष के साथ उसका रिश्ता कहीं दम तो नहीं तोड़ रहा। यहीआशंका हर्ष की बहन सुजाता को भी थी। इसलिए वह हर्ष के मुंबई जाने से पहले वर्षा के साथ उसके विवाह की बात कहती है - "वर्षा पता नही क्यों,मुझे ऐसा लग रहा है कि हर्ष परसों दिल्ली से निकला, तो हमारे हाथ से भी निकल जाएगा। मैं मम्मी को फोन करूं? कल तुम दोनों की शादी हो जाए?" [24] शायद हर्ष के व्यवहार में आए परिवर्तन ने सुजाता को यह सोचने पर मजबूर कर दिया था कि यह रिशता कभी स्थायित्व ग्रहण कर भी पाएगा या नहीं।

परिवार में सब कुछ सहज होने के बाद छोटे भाई के विवाह की बारी है; तब वह बड़ी बहन के लिए सहज चिंता स्वरूप वर्षा से कहता है; मेरा ब्याह तुमसे पहले हो यह अच्छा नहीं लगता । वर्षा अपनी वास्तविकता के अनुरूप सहज होकर कहती है - "मैं तो लंबी दौड़ का धावक हूँ। मेरे साथ बस, मेरा अकेलापन है |" [25] शायद वर्षा ने अपनी आत्मनिर्भरता की कीमत स्वीकार कर ली थी; लेकिन सिद्धार्थ सियाल का प्रपोजल वर्षा के लिए माया नगरी में प्रवेश का नया माध्यम बनता है उसे फिल्म में लीड रोल आफर होता है और स्क्रिप्ट पढ़ कर वर्षा सहर्ष राजी हो जाती है। फिल्म नगरी, में प्रवेश करना वर्षा के लिए अपनी जरूरतों को पूरा करने के साथ आर्थिक सफलता हासिल करना भी था। लेखिका क्षमा शर्मा लिखती है - "इन दिनों स्त्रियों की समझ में यह आ गया है कि
जब तक उनकी आर्थिक स्थिति नहीं सुधरती तब तक उनका विकास नहीं हो सकता क्योंकि दुनिया के $9 ८ \%$ संसाधनों पर पुरुषों का कब्जा है |" [26] अपनी आर्थिक परिस्थिति को सुद्धढ़ करने के लिए वर्षा माया नगरी में अपने अभिनय और अपनी मेहनत से एक महत्वपूर्ण स्थान प्राप्त करती है।

हर्ष एक बड़ा सपना लेकर माया नगरी में प्रवेश करता है; साथ ही सपनों को हकीकत में बदलने के लिए मेहनत की अपेक्षा चालाकी और चतुराई की राह पर चल पड़ता है; फलस्वरूप जहां एक और वह परिवार की बदनामी की वजह बनता है, वही दूसरी ओर फिल्म नगरी में भी अपनी अच्छी छवि नहीं बना पाता लेकिन उसके इस बर्ताव से सबसे अधिक आहत होती हैं, वर्षा वशिष्ठ जिसने हर्ष पर स्वयं से भी ज्यादा विश्वास किया था; लेकिन हर्ष माया नगरी में अपने संघर्ष और अपने स्वार्थ दोनों का यथार्थ बतला कर वर्षा को भरोसा दिला देता है की उसने जो कुछ भी सुना वह सब बेबुनियाद है।

माया नगरी का उतार-चढ़ाव एक और वर्षा वशिष्ठ को सफलतम अभिनेत्री के खिताब के साथ सर्वश्रेष्ठ फिल्म का श्रेय दिलाता है; वहीं दूसरी ओर हर्ष अपनी पहली फिल्म के इंतजार में तनाव में डूबता जाता है; अपनी आदतों, सर्वसुविधा युक्त जीवन शैली का आदि रह चुका हर्ष अपने हर खर्च के लिए वर्षा पर निर्भर होता जाता है। जो वर्षा अपने संघर्ष के दिनों में माया नगरी में एक बरसाती तक जुटाने में स्वयं को असमर्थ पाती थी वही वर्षा आज सफलतम अभिनेत्रियों में शुमार होकर माया नगरी में अपना स्वयं का एक घर खरीदती है। लेकिन हर्ष कहीं न कहीं स्वयं को अपमानित महसूस करते हुए वर्षा को चोट पहुंचाता है। हर्ष अपनी महत्वाकांक्षा पूर्ण नहीं कर पाता और फलस्वरूप वर्षा की सफलता को हजम भी नहीं कर पाता, अंततः हताशा और निराशा से घिर क्र वह वह ड्रग्स का भी आदि हो जाता है ।

वर्षा का अभिनय के प्रति समर्पण और एकाग्रता उसे पुरस्कारों के साथ पद्मश्री तक ले जाता है; वहीं हर्ष असफलता और कुण्ठा से घिर कर अपने ही जीवन का अंत कर लेता है; अंततः अकेली रह जाती है वर्षा वशिष्ठ। लेकिन जीवन के इस भयानक मोड़ पर भी वह अपने स्त्रीत्व के साहस का परिचय देती है" अब मेरे जीवन के हर्ष विहीन अध्याय की शुरुआत हो रही है, उसने सोचा। कितने वर्षों की अंतरंगता, आसंगो और स्मृतियों के साथ अब मुझे नए सिरे से हर्ष के बिना जीने की आदत डालनी होगी |" [27] हर्ष अपनी महत्वाकांक्षा, उससे उपजी हीन भावना और अपने ही असफलताओं की सजा अनजाने ही वर्षा को दे जाता है। वर्षा के लिए अभी और भी कठिन परिस्थितियां उत्पत्न होने वाली थी। हर्ष के अजन्मे बच्चे के भविष्य को लेकर अविवाहित मातृत्व का अत्यंत साहस पूर्ण निर्णय लेना था। किसी सामान्य युवती के लिए इस प्रकार का निर्णय लेना असंभव ही साबित होता लेकिन यहां परिस्थितिवश वर्षा वशिष्ठ को निर्णय लेना था और वह यहां भी यथा नाम तथा गुण वाली कहावत को चरितार्थ करते हुए कुंवारे ममत्व को सहर्ष स्वीकारोक्ति प्रदान करती है | हर्ष की मृत्यु और वर्षा का उसके अजन्मे बच्चे की कुवारीं मां बनने का निर्णय किसी सामान्य स्त्री के बस की बात नही| वर्षा अविवाहित मातृत्व को सहर्ष और सगर्व स्वीकार करती हैं; इतना ही नहीं वह हर्ष के बच्चे को जन्म देकर उसके लालन-पालन का दायित्व कुशलतापूर्वक निर्वहन करती है।

वर्षा के इस संपूर्ण सफर में दिल्ली जैसे महानगर के साथ माया नगरी का भी एक महत्वपूर्ण स्थान रहा है; इन शहरों ने वर्षा को हाथों हाथ लिया उसके कपड़ों, उसके रहने, खाने, सोने औरउसके दोस्तों को लेकर सवाल खड़े नहीं किए। उसके व्यक्तित्व को पंख लगाकर उन्मुक्त आसमान में उड़ने के लिए सकारात्मक परिवेश के साथ स्वस्थ प्रतिस्पर्धा प्रदान कीं। क्षमा शर्मा बड़े शहरों का जिक्र 
करते हुए कहती हैं- “आपके माता-पिता से अधिक आपके पड़ोसी इस बात का ध्यान रखते हैं कि आप कब आती हैं, कब जाती हैं, किससे बात करती हैं, अगर किसी लड़के से बात कर ली तो जब तक बात करने के बाद आप घर तक पहुंचेंगे उससे पहले यह बात पूरे शहर में पहुंच जाती है... हर एक आदमी-औरत वहां निंदा करने के लिए दूसरों के बच्चों का गार्जियन है। जबकि दिल्ली में ऐसा कुछ नहीं है | अक्सर लोग यहां इतने व्यस्त रहते हैं कि दूसरों की जिंदगी में झांकने का मौका नहीं निकाल पाते। इसलिए यह शहर मुझे बहुत पसंद है |" ${ }^{[28]}$ बड़े शहरों की यह एक महत्वपूर्ण विशेषता है कि वे हर व्यक्ति को हर वर्ग को अपने व्यक्तित्व विकास का संपूर्ण अवसर प्रदान करते हैं लेकिन इन्हीं बड़े शहरों में अक्सर व्यक्तित्व इस तरह गुम हो जाते हैं की स्वयं को ही पहचान नहीं पाते क्योंकि अवसरवादी और महत्वाकांक्षा इन बड़े शहरों की सबसे बड़ी खूबी है और हर व्यक्ति इन शहरों को के अनुसार स्वयं को ढाल नहीं पाता |

वर्षा वशिष्ठ सुल्तानगंज नामक छोटे कस्बे से निकलकर दिल्ली जैसे महानगर और अंततः मुंबई जैसी महानगरी में अपने संघर्ष साहस और प्रतिभा के दम पर सपनों को साकार करती है। वह परिवार समाज एवं परंपरा के नाम पर आधी आबादी पर लगाई जाने वाली वर्जनाओ, मान्यताओं को ठुकरा कर अदम्य साहस व स्वाभिमान का परिचय देकर; अनंत संभावना के आसमान में उन्मुक्त उड़ान के साथ अपने हौसलों को उस चरमोत्कर्ष तक पहुंचाती है, जहां पहुंचना असंभव की श्रेणी में रखा जा चुका है। 'मुझे चाँद चाहिए' सिर्फ वर्षा वशिष्ठ की ही कहानी नहीं है वरन यह वर्तमान परिवेश में आधी आबादी को अपने व्यक्तित्व, अपनी स्वतंत्र एवं आत्मनिर्भर छवि के लिए संघर्षरत रहने की प्रेरणा भी है।

\section{संदर्भ}

1. वर्मा सुरेंद्र- मुझे चांद चाहिए, पृष्ठ- 14

2. शर्मा क्षमा: स्त्रीत्ववादी विमर्श: समाज और साहित्य, पृष्ठ -9

3. वर्मा सुरेंद्र- मुझे चांद चाहिए, पृष्ठ-15

4. वर्मा सुरेंद्र- मुझे चांद चाहिए, पृष्ठ- 17

5. वर्मा सुरेंद्र- मुझे चांद चाहिए, पृष्ठ- 18

6. वर्मा सुरेंद्र- मुझे चांद चाहिए, पृष्ठ- 23

7. वर्मा सुरेंद्र- मुझे चांद चाहिए, पृष्ठ- 13

8. वर्मा सुरेंद्र- मुझे चांद चाहिए, पृष्ठ- 24

9. शर्मा क्षमा: स्त्रीत्ववादी विमर्श: समाज और साहित्य, पृष्ठ-13

10. वर्मा सुरेंद्र- मुझे चांद चाहिए, पृष्ठ- 26

11. वर्मा सुरेंद्र- मुझे चांद चाहिए, पृष्ठ- 40

12. वर्मा सुरेंद्र- मुझे चांद चाहिए, पृष्ठ- 28

13. शर्मा क्षमा: स्त्रीत्ववादी विमर्श: समाज और साहित्य, पृष्ठ- 12

14. वर्मा सुरेंद्र- मुझे चांद चाहिए, पृष्ठ-48

15. वर्मा सुरेंद्र- मुझे चांद चाहिए, पृष्ठ-77

16. वर्मा सुरेंद्र- मुझे चांद चाहिए, पृष्ठ- 88

17. वर्मा सुरेंद्र- मुझे चांद चाहिए, पृष्ठ-103

18. वर्मा सुरेंद्र- मुझे चांद चाहिए, पृष्ठ- 115

19. वर्मा सुरेंद्र- मुझे चांद चाहिए, पृष्ठ-118

20. शर्मा क्षमा: स्त्रीत्ववादी विमर्श: समाज और साहित्य, पृष्ठ-14

21. वर्मा सुरेंद्र- मुझे चांद चाहिए, पृष्ठ-142

22. वर्मा सुरेंद्र- मुझे चांद चाहिए, पृष्ठ-205

23. वर्मा सुरेंद्र- मुझे चांद चाहिए, पृष्ठ-216

24. वर्मा सुरेंद्र- मुझे चांद चाहिए, पृष्ठ- 242

25. वर्मा सुरेंद्र- मुझे चांद चाहिए, पृष्ठ- 286

26. शर्मा क्षमा: स्तीत्ववादी विमर्श: समाज और साहित्य, पृष्ठ-19

27. वर्मा सुरेंद्र- मुझे चांद चाहिए, पृष्ठ-550

28. शर्मा क्षमा: स्त्रीत्ववादी विमर्श: समाज और साहित्य, पृष्ठ-38 